be the result of prolonged intrauterine compression. The rarity of reports of these tumours occurring in preterm infants may be attributed to the relatively large cushioning volume of liquor amnii. The 2 cases here reported occurred in the second placed infants of twins in pregnancies with prolonged loss of liquor before delivery. They therefore seem at risk to postural deformity despite their prematurity. Case 1 was delivered by caesarean section, adding to the list of documented sternomastoid tumours occurring in infants so delivered, which seems further evidence that these tumours are not the result of birth injury.

I thank Dr D. Pickering and Dr D. Baum for permission to report these cases.

M. BAMFORD

Department of Paediatrics, The Radcliffe Infirmary, Oxford $O X 26 H E$.

References

Dunn. P. M. (1974). Congenital sternomastoid torticollis: an intrauterine postural abnormality. (Abst.) Archives of Disease in Childhood, 49, 824-825.

Jones, P. G. (1968). Torticollis in Infancy and Childhood. Thomas, Springfield, Illinois.

\section{Total anomalous pulmonary venous drainage in sibs}

Sir,

We would like to bring to your attention the rare occurrence of total anomalous pulmonary venous drainage (TAPVD) in sibs.

Case 1. A male, the first-born of a 23-year-old mother, was delivered at term, birthweight $2440 \mathrm{~g}$. After doing well initially he was admitted to hospital aged 2 months with cyanosis, heart failure, and an associated murmur. $\mathrm{He}$ was treated with digoxin, frusemide, and antibiotics (for an associated pneumonia), and was referred to the Transvaal Memorial Hospital for Children aged $3 \frac{1}{2}$ months.

Cardiac investigation showed TAPVD of the supracardiac type draining into the innominate vein with no obstruction to the ascending vertical vein. At age 4 months he underwent total correction, but during induction of anaesthesia had a cardiac arrest. He was resuscitated and an anastomosis of the confluence of the pulmonary veins to the left atrium was accomplished under profound hypothermia. Over the 12 hours after surgery his condition worsened and he died without regaining consciousness.

Case 2. A boy was the first-born of nonidentical twins in the mother's third pregnancy, the second pregnancy being normal with delivery of a term female. His birthweight was $2270 \mathrm{~g}$. Both he and his twin sister appeared to do well until 3 months of age when he had a cyanotic spell and was admitted with bronchopneumonia and in heart failure. He failed to respond adequately to anti- biotics, digoxin, and frusemide, and was transferred to Transvaal Memorial Hospital aged 4 months.

Cardiac investigation again showed TAPVD. Angiography, although showing the ascending vertical vein draining into the innominate vein, did not clearly define a common chamber, because the anomalous pulmonary veins were found to drain into both the common vertical vein and the coronary sinus (mixed type). The lesion was corrected by anastomosis of the common chamber to left atrium and moving the atrial septum across so that coronary sinus drained into left atrium. $\mathrm{He}$ is alive and well at age 11 months.

In this family the eldest boy and the youngest bcy (who was one of nonidentical twins) both had TAPVD. Few instances of familial occurrence of TAPVD have been described. Gathman and Nadas (1970) were probably the first in noting 2 sibs among 75 patients with TAPVD. Paz and Castilla (1971), from Argentina, then described 2 male sibs with supradiaphragmatic TAPVD and a male cousin with infradiaphragmatic TAPVD. 2 male sibs with identical type of infradiaphragmatic TAPVD were reported from Australia (Clarke et al., 1973). These authors mention another family from the south of France, where both sibs had the infradiaphragmatic form of TAPVD. Delisle et al. (1976), in their large series of postmortem cases, describe a familial instance of TAPVD to the coronary sinus in one and subdiaphragmatic in the other sib. They also describe TAPVD in two sets of identical twins where the lesion was present in only one of each pair.

To the best of our knowledge there are 7 families where 15 instances of TAPVD have occurred. Furthermore, only 3 sets of twins ( 2 sets identical, 1 set nonidentical) have been reported and in each instance only 1 twin has been affected.

SELWYN MILNER, SOLOMON E. LEVIN,
PAUL E. MARCHAND, and
FRANCOIS HITCHCOCK
Departments of Paediatrics,
Cardiology and Thoracic Surgery,
and J. G. Strijdor Chospital,
Transvaal Memorial Hospital for Hity of the Witwatersrand,
University
Johannesburg, Republic of South Africa.

\section{References}

Clarke, C. P., Edis, B. D., and Danks, D. M. (1973). Familial total anomalous pulmonary venous return. (Abst). Australian and New Zealand Journal of Medicine, 3, 629.

Delisle, G., Ando, M., Calder, A. L., Zuberbuhler, J. R., Rochenmacher, S., Alday, L. E., Mangini, O., Van Praagh, S., and Van Praagh, R. (1976). Total anomalous pulmonary venous connection. Report of 93 autopsied cases with emphasis on diagnostic and surgical consideration. American Heart Journal, 91, 99-122.

Gathman, G. E., and Nadas, A. S. (1970). Total anomalous pulmonary venous connection. Clinical and physiologic observations of 75 pediatric patients. Circulation, 42, 143-154.

Paz, J. E., and Castilla E. E. (1971). Familial total anomalous pulmonary venous return. Journal of Medical Genetics, 8, 312-314. 